\title{
Causes of Germanium Phosphide Degradation under Prolonged Cycling. EIS Study
}

Tatiana Kulova ${ }^{1}$, Dmitrii Gryzlov ${ }^{1}$, Alexander Skundin ${ }^{1}$, Ilya Gavrilin ${ }^{1,2}$, Irina Martynova ${ }^{2}$, Yulia Kudryashoval

${ }^{1}$ Frumkin Institute of Physical Chemistry and Electrochemistry of the Russian Academy of Sciences, 31-4 Leninskii ave., 119071 Moscow, Russia

${ }^{2}$ National Research University of Electronic Technology (MIET), Bld. 1, Shokin Square, Zelenograd, 124498, Moscow, Russia

*E-mail: askundin@mail.ru

Received: 1 November 2021 / Accepted: 2 December 2021 / Published: 5 January 2022

Negative electrodes (anodes) of a germanium-phosphide-based sodium-ion battery were cycled at different current densities. Germanium phosphide impedance spectra were measured and analyzed for different cycles. It was found that prolonged cycling at low current densities $(0.02 \mathrm{C})$ leads to an increase in the resistance of the solid electrolyte film and the consequent increase in the effective charge transfer resistance. It was concluded that changes in these equivalent circuit parameters cause the degradation of germanium phosphide under cycling.

Keywords: germanium phosphide, sodium-ion battery, impedance spectroscopy, degradation, cycling.

\section{$\underline{\text { FULL TEXT }}$}

(C) 2022 The Authors. Published by ESG (www.electrochemsci.org). This article is an open access article distributed under the terms and conditions of the Creative Commons Attribution license (http://creativecommons.org/licenses/by/4.0/). 